\title{
Peer-led academic learning: a global network
}

\section{Chris Keenan}

Bournemouth University, UK

\section{Abstract}

There is a great deal of evidence to support the view that there are a significant number of benefits to be gained when more experienced students are trained to guide and facilitate less experienced learners. Peer-led academic learning is an increasingly global phenomenon and some UK schemes have been in existence since the early 1990s. In view of this, it was timely for the UK Higher Education Academy (HEA) to commission a report to explore the range and scope of UK schemes, reflect on progress so far, and identify opportunities for future developments. This opinion piece will provide a brief overview of the report findings, and will describe the development of a new world-wide network for practitioners to share their ideas/practice. The new network will also offer opportunities for collaborative research in this exciting area of student experience.

Keywords: peer-led learning; student-led peer learning; student retention; student experience.

\section{Introduction}

The 'Mapping student-led peer learning in the UK' report (Keenan, 2014) was commissioned and published by the HEA. Written in partnership with Marcia Ody of the University of Manchester, the report aimed to provide a picture of the scope and range of peer-led learning activity in the UK, offer examples of innovative practice, provide a global perspective of peer-led learning activity, and make recommendations for future developments in the field. The data for the report were gathered through a survey and participants were encouraged to offer examples of their innovative and creative practice for short case studies. This article will provide some of the key findings of the report. It will also highlight two key outputs of the work. Firstly, participants and others in the sector 
were invited to contribute to a special edition of JLDHE (to be published in November 2015) in order to develop their small case studies, research and experiences in publications Secondly, a new network has been established for everyone interested in all forms of student-led academic learning and this will be expanded upon later in this piece.

\section{Overview of the 'Mapping student-led peer learning in the UK' report}

There are a growing number of recent studies that demonstrate and provide evidence for the benefits of peer-led academic learning that build on the early work of seminar authors such as Vygotsky. More recent studies (Keenan, 2011; 2012; Baldry Currens and Coyle, 2013) explore the value of schemes within practice, for example in STEM and Health Sciences, and as approaches for improving retention and progression (Foster et al., 2011). Other recent studies set out to explore peer-led academic learning through the lens of social and cognitive theories (Hilsdon, 2013) and within the broad context of peer education (Ody, 2013) in order to develop better understandings of the phenomenon taking place.

The 'Mapping student-led peer learning in the UK' report (Keenan, 2014, p.8) had broad aims which were to explore through a survey the scope and range of peer-led learning activity in the UK, invite examples of innovative practice, place the UK activity within the global context, and make recommendations for future developments. The working definition of peer-led learning for this purpose was 'the practice of more experienced students being trained to guide and facilitate the learning of less experienced students in an organised and supported way' (Keenan, 2014, p.5). Data were gathered through a survey distributed in the spring of 2014. Analysis of the data made it increasingly apparent that there was an appetite to develop this area as a field of research and practice, and some examples of innovation in practice and research were included within the final report. It was important to place the UK activity within the global peer learning context and short reports from Australia, South Africa, Canada, Sweden and the USA were also included.

Four of the key findings of the report state:

- The prevalence of peer-led learning schemes is increasing across disciplines and institutions in the UK and internationally. 
- Partnership is built between students, peer leaders, tutors and the wider community.

- Institutions gain substantial reputational advantage from demonstrating commitment to building student engagement, community partnerships, progression and retention.

- Participation in national networks, collaborative practice and research is invaluable.

The report identified a wide range of approaches to the organisation and operation of schemes, however, they tended to follow similar basic principles. For example, they:

- Support student learning.

- Foster cross year support for students.

- Enhance students' experience of university life.

- Create a safe environment where students are encouraged to ask questions.

It was reported that students who engage in peer-led learning sessions experience less anxiety around their transition to university, feel a greater sense of belonging, and outcomes suggest there is improved academic confidence. Leaders acquire higher level skills that underpin their personal and professional development, which in turn improves their employability prospects. They also develop a deeper understanding of their subject and enhanced social and inter-cultural awareness. Schemes appear to help institutions meet their strategic goals relating to progression and retention of students and improved student satisfaction.

In order to avoid a positive bias, the survey also asked respondents to identify challenges that might be encountered and advice about how to overcome those challenges. Amongst the identified challenges respondents spoke of a need for robust data to support the implementation and embedding of schemes. It was felt that a lack of data and information could be an obstacle to gaining buy-in from other stakeholders.

Finally, the report offered a number of recommendations which included:

- The importance of strategic leadership and support.

- The importance of mainstreaming schemes within the curriculum. 
- That a broad group of stakeholders, including employers, should be engaged in the activities.

\section{Towards a new community of practice}

A further important recommendation of the 2014 report was that:

The national and international peer-learning community should promote the sharing of practice, undertake pooling of data and collaborative research into the participative pedagogies, and build a bank of impact studies. (Keenan, 2014, p.44)

During the writing up of the report, it became increasingly apparent that there was a great deal of energy, enthusiasm and commitment amongst practitioners. It was felt that a new network for all practitioners working in the field of peer-led academic learning would be welcomed. This new network would embrace all approaches, whether formal or informal, whether or not based on the supplemental instruction model, and with any focus, for example, within Science Technology Engineering and Mathematics (STEM) or the Arts, including peer-led academic writing, peer-led academic learning support for students from diverse widening participation backgrounds, and for international students. It was felt that such a forum would be well placed to share advice and practical support, share practice, share and develop resources, and potentially collaborate on large scale world-wide impact studies that would offer an evidence base to support the benefits of schemes. It would also offer practitioners the opportunity to work together beyond international boundaries on developing important research in this field.

In order to underpin this new network with a sustainable framework, Marcia Ody and I approached the Association for Learning Development in Higher Education (www.aldinhe.ac.uk). ALDinHE is an independent organisation with strong membership and international affiliations. Many members of the learning development community are already engaged in peer-led learning activities and there is a clear alignment of interests between the association and this new network. It was also felt that a range of stakeholders should be involved in the setting up of the new network in order to ensure that all voices were represented, and an advisory group was therefore brought together to support the network development. This advisory group is representative of the international 
community, students' union, practitioners, researchers, disciplinary groupings, and those who have experience of embedding and sustaining schemes.

It was with great excitement that the new network for academic peer learning was launched on 10 June 2015 during the Peer Education event held at the University of Manchester. News of the new network was circulated via existing networks and word of mouth, and within four weeks of the launch we already have 189 subscribers, representing 122 different institutions/organisations from 11 countries worldwide. This extraordinary growth is heart-warming evidence of the desire for, and importance of, such a network and grouping of people who share a common passion for this most interesting and exciting aspect of student learning and development.

New subscribers to the network are introducing themselves and generously sharing their interests, experiences and findings with the wider group. Already there have been powerful and interesting discussions taking place across a variety of themes:

\section{Socio-cultural}

- Overcoming discipline-based stereotypes and gender barriers.

- Building community.

- Staff/student perspectives of schemes.

\section{Peer leader development}

- Training and evidencing leader development.

\section{Broad approaches}

- Asynchronous discussion forums.

- Academic writing, discourse and class.

- Overview of individual schemes and approaches.

- Transition support for international students > effective study practices.

- Chemistry, health professions.

- Pre-arrival widening participation.

- Disability and mental health - embracing diversity workshop. 


\section{Sharing experiences of setting up schemes}

- Introducing new schemes.

- Managing large programmes.

\section{Research}

- Links to critical literacies, participative pedagogies, etc.

- Practices to facilitate critical literacies.

\section{Evaluation of schemes}

- Measure and impact of schemes.

- Leader employability.

- Sharing of survey data and PowerPoint presentations.

- Success factors.

A lack of robust data had been cited in the mapping peer-led academic learning report as a potential obstacle in persuading policy makers of the benefits of introducing new schemes or continuing existing ones, and this new network, or community of practice, has potential to address this through collaborative ventures.

In order to move the evaluation/research agenda forward, an impact/research special interest group (SIG) has been set up within the new academic peer learning network. The broad aims of this SIG are to determine key impact measures, share evaluation practices and coordinate collaborative research. A specific priority of the group will be to develop a large impact study aligned to the recommendations of the 'Mapping student-led peer learning in the UK' (Keenan, 2014) report. Already network members from 26 institutions including the UK, Canada, Australia, the USA and South Africa have expressed interest in collaborating on this. The methodology for the initial study is still under discussion but early thinking is to find out what data institutions are already collecting to evaluate their peer-led learning schemes. The SIG will also hope to analyse existing surveys to ascertain if there is any data that is close enough to evidence impact across the SIG institutions. It is anticipated that some of this initial analysis will be carried out at Bournemouth University in the UK during August 2015.

The new academic peer learning network is already developing into a friendly, supportive community of practice where practitioners can share practice, share ideas, and collaborate 
on creating an evidence-based, research informed field of practice, and it is exciting to see one of the recommendations of the 'Mapping student-led peer learning in the UK' report coming to life. It is anticipated that the new community will not only provide a source of mutual advice and support, particularly around implementing, embedding and sustaining schemes, but that it will contribute to the development of resources for LearnHigher and provide a strong basis for collaborative international research.

Finally, the special edition due to be published in November 2015 will include a broad and international picture of academic peer-led learning practice and is expected to be a bumper edition given the overwhelming expression of interest.

\section{References}

Baldry Currens, J.A. and Coyle, J. (2013) 'Practice-based learning: multiple dimensions and the importance of 'others", in Higgs, J., Sheehan, D., Baldry Currens, J., Letts, W. and Jensen, G.M. (eds.) Realising exemplary practice-based education. Rotterdam: Sense Publishers, pp. 81-90.

Foster, E., Keenan, C. and Colley, B. (2011) The HERE project 2008-2011 final report 2011. Available at: https://www.heacademy.ac.uk/resources/detail/what-worksstudent-retention/HERE Project What Works Final Report (Accessed: 19 July 2015).

Hilsdon, J. (2013) 'Peer learning for change in higher education', Innovations in Education and Teaching International, 51(3), pp. 244-54 [Online]. Available at: http://dx.doi.org/10.1080/14703297.2013.796709 (Accessed: 19 July 2015).

Keenan, C. (2011) Peer assisted learning: in and beyond the classroom. Available at: http://www.hestem.ac.uk/activity/peer-assisted-learning-and-beyond-classroom (Accessed: 19 July 2015).

Keenan, C. (2012) The role of peer assisted learning in supporting student transition to HE STEM programmes: from a PAL leader's perspective. Available at: http://hestemsw.org.uk/project?id=13\&pp=531 (Accessed: 19 July 2015). 
Keenan, C. (2014) Mapping student-led peer learning in the UK. Available at: https://www.heacademy.ac.uk/node/10208 (Accessed: 19 July 2015).

Ody, M. and Carey. W. (2013) 'Peer education', in Morgan, M. (ed.) The student engagement handbook practice in higher education. Bingley: Emerald Group Publishing Ltd., pp. 291-312.

\section{Author details}

Chris Keenan is a Learning and Teaching Fellow in the Faculty of Applied Science and Technology, Bournemouth University. 